\title{
Interpretación tafonómica y paleobiológica de las ruinas romanas del Cerro del Trigo en Doñana, Huelva
}

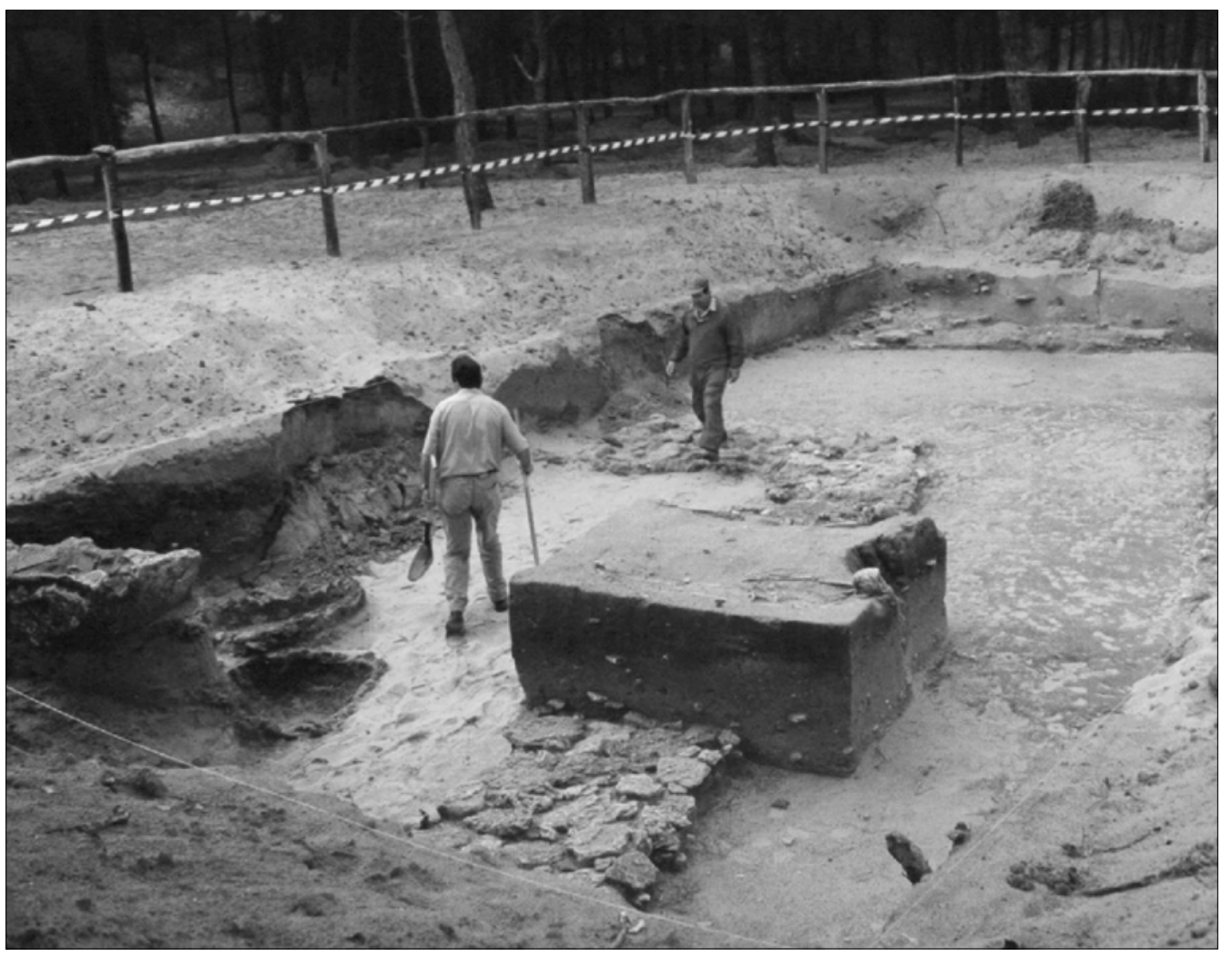

Vista general del yacimiento romano del Cerro del Trigo

Eloísa Bernáldez Sánchez

María Bernáldez Sánchez

Laboratorio de Paleobiología del IAPH

\section{Resumen}

El análisis paleobiológico y tafonómico de los elementos orgánicos asociados a las estructuras arqueológicas romanas de los siglos II y VI d.C. del Cerro del Trigo, situado en Almonte -Huelva-, muestran un aporte importante en material malacológico, en relación con la aportación de los vertebrados. La escasez de restos óseos de los que obtener datos biométricos suficien- tes no nos permite extrapolar los resultados obtenidos a la población de ganado consumido ni a la población de la comunidad silvestre, aunque sí nos permite estimar las diferencias y similitudes entre los depósitos formados. Por el contrario, hallamos en un número estadísticamente suficiente valvas de almendras de mar-Glycimeris glycimeris- que nos ha servido para determinar las diferencias entre esta asociación y la del yacimiento romano del siglo IV d.C. El Eucaliptal, situado en la misma línea de la costa onubense, en la localidad de Punta Umbría.

\section{Palabras clave}

Paleobiología / Tafonomía / Bioestratinomía / Vertebrados terrestres / Malacofauna. 

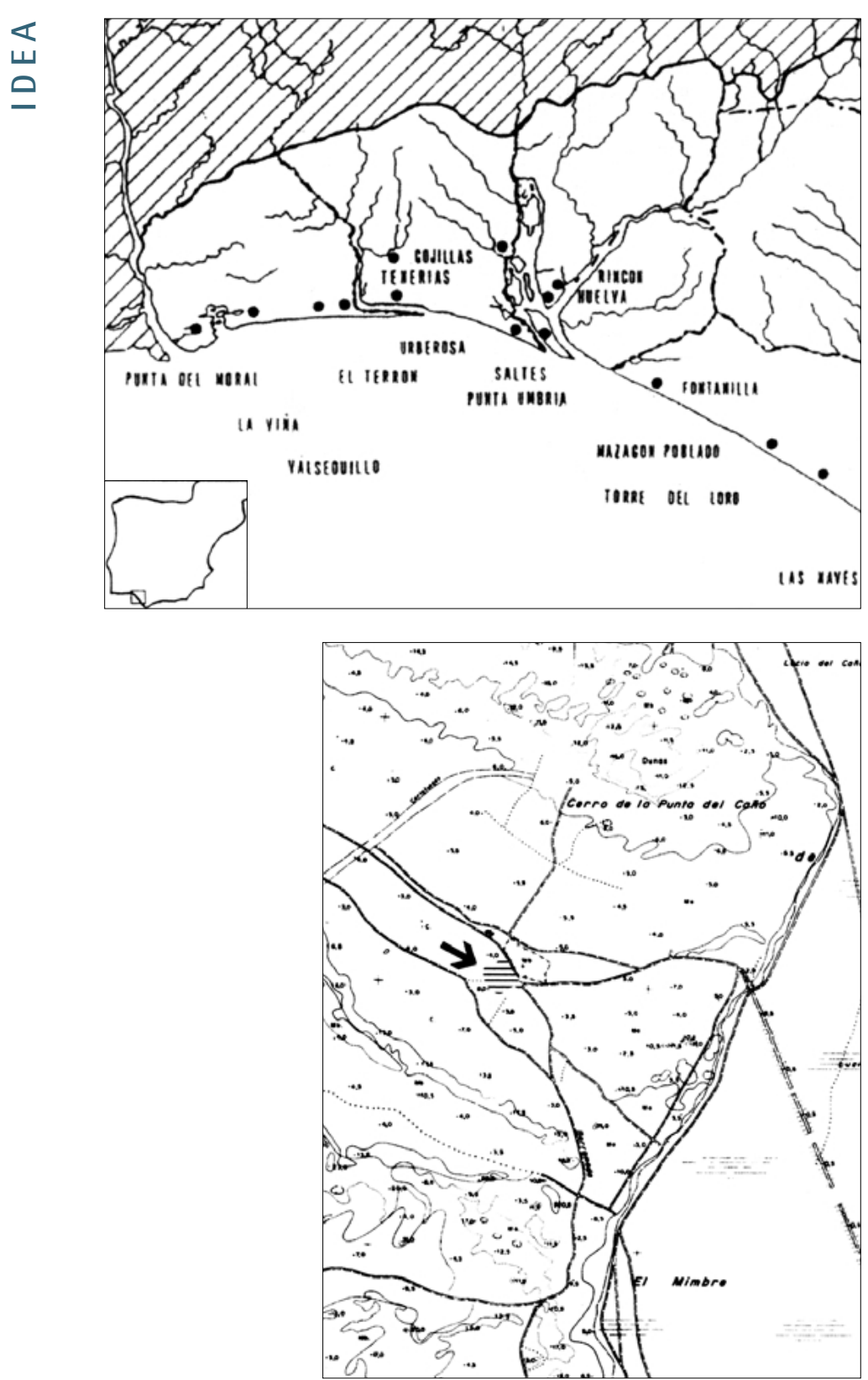

"La romanización y la consiguiente explotación económica del territorio de la actual provincia de Huelva es uno de los aspectos menos abordados por la investigación arqueológica que se ha desarrollado en ella". Éste es el primer comentario que aparece en la introducción de Las Cetariae del litoral onubense en época romana de Campos et all. (1999) para explicar el interés de dar a conocer la importancia del litoral en el desarrollo económico de esta provincia. El descubrimiento y el estudio de las antiguas fábricas romanas de salazones tienen, en este territorio, la relevante continuidad que hasta ahora no se le había dado a Huelva entre los enclaves litorales del Golfo de Cádiz.

Dos de esos enclaves pesqueros-fabriles han sido estudiados desde el punto de vista de la paleobiología y la tafonomía, el Cerro del Trigo en el Parque Nacional de Doñana y El Eucaliptal en Punta Umbría. Según las conclusiones de los arqueólogos, ambas poblaciones vivieron básicamente de esta actividad desde principios del siglo II d.C hasta comienzos del siglo VI d.C., siendo los siglos II y $\vee$ los más relevantes. A estos dos siglos pertenecen los vertederos encontrados en el yacimiento de El Cerro del Trigo y a partir de ellos intentaremos contar otra, o la misma historia, desde otro punto de vista, el de la basura orgánica.

\section{LOS DEPÓSITOS DE RESTOS PALEOORGÁNICOS}

Entre las ruinas romanas datadas en los siglos II y VI d.C. localizadas en la zona de dunas del Parque $\mathrm{Na}$ cional de Doñana -Huelva- se formaron depósitos de restos orgánicos procedentes de vertebrados y conchas de moluscos. Estos depósitos han sido analizados desde el punto de vista de las funciones ecológicas del hombre en este determinado ecosistema costero y de los procesos bióticos y abióticos que pueden intervenir en el origen y posterior conservación del depósito hasta su exposición durante los trabajos de excavación realizados en 1999 por el equipo de arqueólogos (Campos el all, 200I).

Una vez extraído el material paleoorgánico y preparado para su estudio en el laboratorio, se determinó la variedad de especies que integra la asociación faunística a través de la identificación de las conchas y de los fragmentos de huesos conservados. El análisis de los datos viene determinado por los objetivos comunes con otros yacimientos y por las particularidades de esta excavación. Así exponemos que el principal objetivo común es determinar las características del contenido como valor identificador de las costumbres del agente o de los agentes que lo originaron, el segundo objetivo es entender espacialmente la distribución de estos depósitos en el conjunto arqueológico en referencia a otros yacimientos.

Entre los objetivos particulares está el analizar la diversidad de especies enterradas en relación con la comunidad actual, lo que requiere un estudio bioestratinómico de Doñana sobre la formación de depósitos de restos orgánicos y su relación con la comunidad terrestre y marina. Como objetivo último consideramos el estudio comparativo con el yacimiento romano de El Eucaliptal en Punta Umbría, en la misma costa onubense.

El contenido estudiado fue rescatado de cuatro cortes de dimensiones distintas realizados en un radio de $50 \mathrm{~m}$. De cada uno de ellos se extrajo el material orgánico según la técnica establecida por el equipo de arqueólogos, atendiendo a unidades estructurales que fueron datadas en distintos períodos romanos comprendidos en los siglos II y VI d.C.

Los cortes estudiados responden a los que contienen restos paleoorgánicos con las numeraciones I, 4, 6 y 8 y en cada uno de ellos encontramos restos orgánicos en las unidades 3 del corte 1; I del corte 4; $3,6,10,12$ y 13 en el corte $6 ;$ y 3,6 y 11 en el cor- 
te 8 (esquemas 1, 2 y 3). Para esta primera parte del estudio, los datos analizados corresponden al número de especies identificadas -NSP- y al número mínimo de individuos estimado a partir de las partes anatómicas encontradas -NMI-, para la asociación de especies de vertebrados terrestres, y al número de elementos -NE: valvas y caracoles-, además, para la malacofauna. Los elementos que se hallaban en buen estado de conservación son medidos con el objetivo de deducir a partir de su biometría la causa de estos depósitos, sobre todo, para la malacofauna cuyo origen puede ser debido a la recolección humana y/o a la formación de concheros naturales.

Con estos datos y los criterios biológicos, tafonómicos, bioestratinómicos e históricos se pretende determinar el tipo de basurero, su validez como representación de las costumbres de los pobladores del Cerro del Trigo durante el tiempo datado, sus diferencias con la comunidad faunística actual y su asociación de cadáveres correspondiente formada en Doñana (Bernáldez, 2002a). Ante la urgencia de este primer estudio se ha seleccionado la especie malacológica más frecuente y abundante en todas las unidades de esos cortes, por ello basamos nuestro estudio biométrico sobre la especie Glycimeris glycimeris o almendra de mar; cuyo origen en el depósito nos llama la atención puesto que en la actualidad no es una especie de consumo.

\section{EL CONTENIDO PALEOORGÁNICO DE LOS DEPÓSITOS}

Para describir y cuantificar el contenido orgánico de estos cortes consideramos el volumen excavado total, el de cada corte y el de cada unidad estratigráfica que registrase material orgánico; de este modo, obtenemos una variable con la que estimar el espacio ocupado por la basura en los distintos depósitos y un gradiente de uso de esos lugares para arrojar desechos.

En primer lugar, mostraremos dónde está la basura orgánica y qué volumen ocupa en la estratigrafía de El Cerro del Trigo. De los cortes realizados por los arqueólogos, cuatro contenían restos paleoorgánicos. La mayoría de los restos de vertebrados (vacas, caballos, cerdos, caprinos, pollos, peces) proceden del consumo humano, según los cortes de carnicería, concentrándose en las unidades de ocupación romana de tres cortes. Los cortes 1 y 8 se sitúan a 90 m al Sur de la Casa del Guarda y el corte 6 en la zona delantera de El Cerro de la Cebada.

El registro de vertebrados terrestres ha sido de 129 huesos de 41 individuos cuyas masas corporales van desde los más de $410 \mathrm{Kg}$ de las vacas hasta la masa de una perdiz. Casi todos los huesos de los ungulados, vacas, cerdos y caprinos, presentan cortes de carnicería; por el contrario, las piezas óseas de pequeños carnívoros, lagomorfos (conejo) y pequeñas aves, están completos y conservan sus superficies en buen estado, lo que demuestra que fueron inmediatamente enterrados y no necesariamente por el hombre.
Del total de ejemplares estimados y de huesos hallados, el $90 \%$, se encuentra en las unidades de ocupación romana, sólo el 10\% era parte de un relleno de las trincheras excavadas a principios del siglo XX por G. Bonsor y A. Schulten. Así que trataremos el estudio sistemático de los cortes que forman parte de una estratigrafía aparentemente no removida desde su origen, los corte 1, 6 y 8.

El volumen total de los tres cortes estudiados, 1,6 y 8 , con fauna de vertebrados es de $181.07 \mathrm{~m}^{3}$ de los cuales $68.44 \mathrm{~m}^{3}$ corresponden a unidades con restos paes uniforme en todos los cortes; así en el corte I que tenía $53.40 \mathrm{~m}^{3}$ la suma de las unidades con material paleoorgánico es de $5.32 \mathrm{~m}^{3}$, un 9.96\%; en el corte 6 el porcentaje de volumen en el que se registró este material, de un total de $22.46 \mathrm{~m}^{3}$, fue del $52.72 \%$ I I.84 m³ - y el corte 8 contenía $51.28 \mathrm{~m}^{3}$ con materia paleoorgánica observable en un total de $105.21 \mathrm{~m}^{3}$, es leoorgánicos, un 37.8\% del total. Este porcentaje no

Restos paleoorgánicos de vertebrados e invertebrados. Hay una relativa abundancia de la malaco-

fauna y de una cierta especie. Glycimeris glycimeris

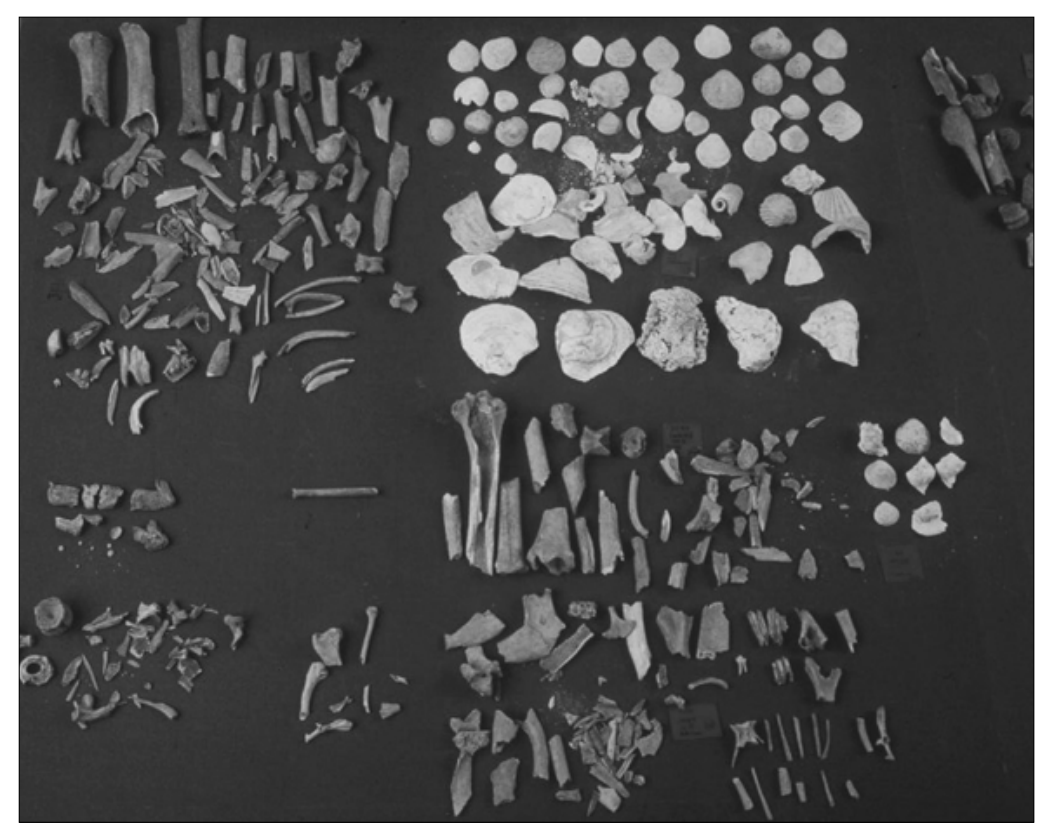

Fig. 1. Cerro del Trigo en Doñana. Contenido de basura orgánica. Del volumen total excavado en cada corte en estudio hay un porcentaje ocupado por basura orgánica procedente de vertebrados e invertebrados terrestres y marinos

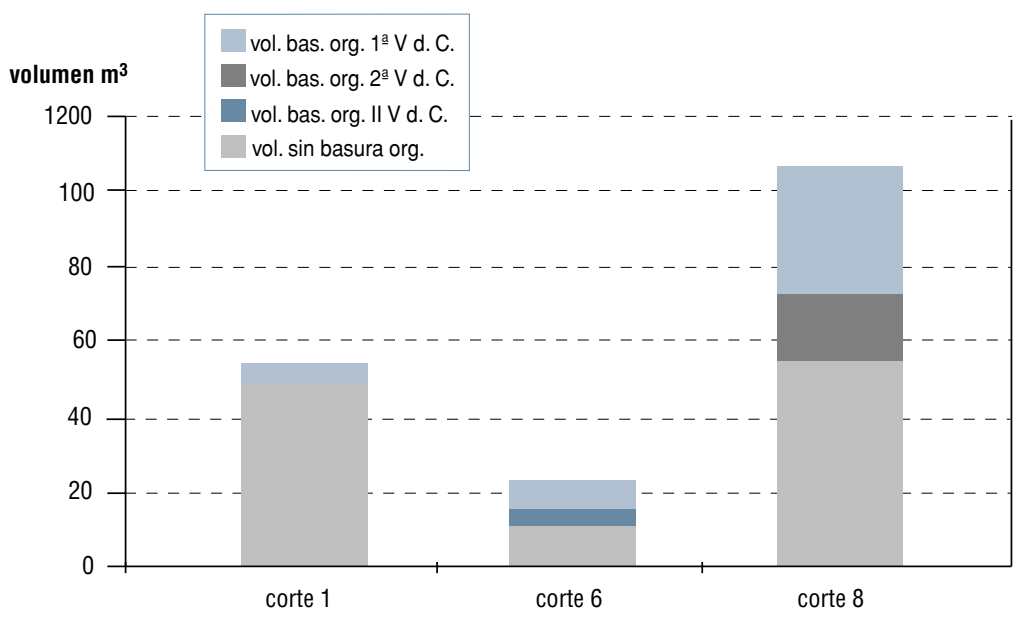


$\longleftarrow$
$\square$ decir, el 48.74\%. Desde el punto de vista tafonómico, de la formación y constitución de estos depósitos, la basura orgánica, como icnita de la actividad humana, diferencia al corte I de los otros dos; puesto que en el I el $10 \%$ del volumen total contiene desechos paleoorgánicos observables, mientras que en los cortes 6 y 8 la basura ocupa la mitad o algo más del volumen excavado -fig. IEsto tiene fuertes implicaciones en la estratigrafia de EI Cerro del Trigo en los dos y tres primeros $m$, cuyos estratos tienen su origen tanto en la actividad desarrollada por el hombre como por los agentes naturales. Así que encontramos el nivel de ocupación romana entre dos niveles de arenas, la más profunda sobre la que se instalaron y la que finalmente ocultó las ruinas romanas.

De modo que, mientras el corte I contiene el 7.77\% del volumen total excavado ocupado con desechos orgánicos, el 75\% del volumen con basura corresponde al corte 8; aunque es cierto que el volumen excavado en ambos es distinto, sin embargo, no es proporcional al volumen ocupado por la basura. El corte 8 supone el $58.1 \%$ del volumen total excavado y el corte I el 29.5\%. En el corte 6 tenemos que siendo menos de la mitad del volumen de este últi-

Tabla 1. Cantidades y proporciones de volumen con desechos paleoorgánicos. Yacimiento romano del Cerro del Trigo de Doñana -Huelva-

\begin{tabular}{cccccc}
\hline CORTE & $\begin{array}{c}\text { VOLUMEN } \\
\text { EXCAVADO }\end{array}$ & $\%$ & $\begin{array}{l}\text { VOLUMEN } \\
\text { BASURA }\end{array}$ & $\%$ & $\begin{array}{l}\text { VOL.BAS./ } \\
\text { VOL.EXC. }\end{array}$ \\
\hline 1 & 53.40 & 29.5 & 5.32 & 7.77 & 9.96 \\
\hline 6 & 22.46 & 12.4 & 11.84 & 17.3 & 52.72 \\
\hline 8 & 105.21 & 58.1 & 51.28 & 75.4 & 48.74 \\
\hline TOTAL & 181.07 & & 68.44 & & \\
\hline
\end{tabular}

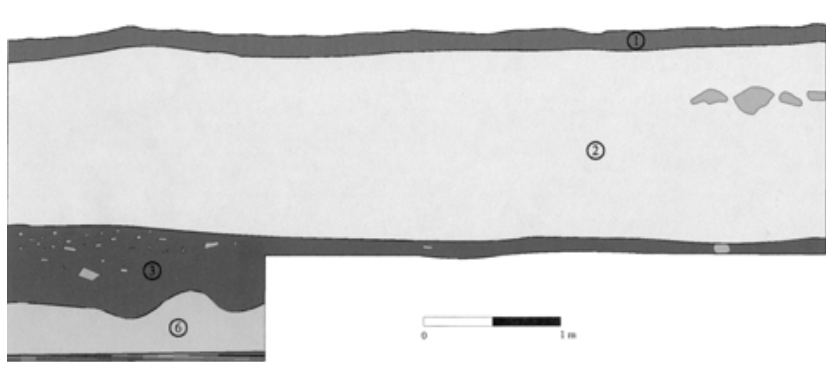

Corte 1 .
Perfil Oeste

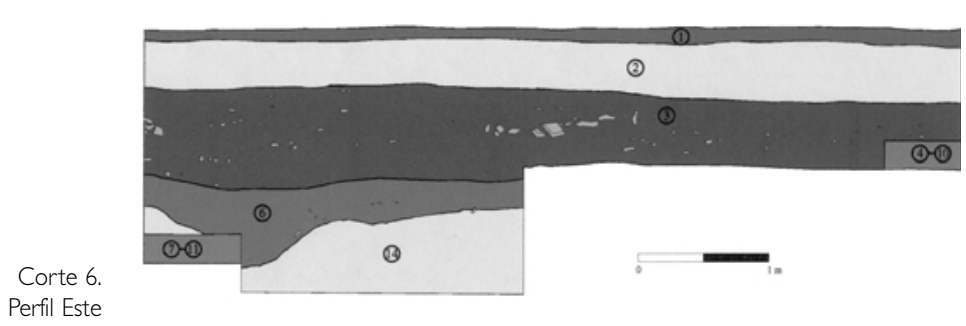

Perfil Este

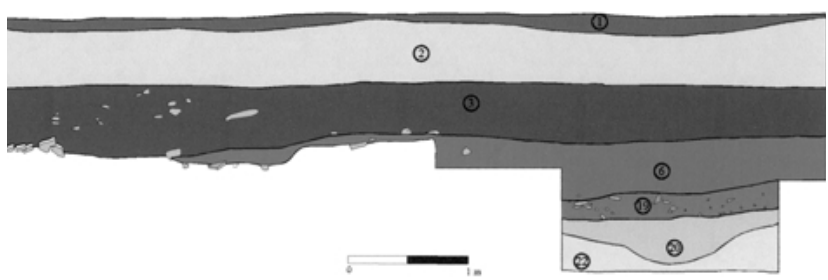

mo, los niveles con basura orgánica ocupan el 17.3\% del volumen total excavado; además, es proporcionalmente similar al corte 8: cuando aumentamos el volumen excavado en cinco veces, aumenta cinco veces el volumen de los niveles basureros.

Que encontremos una buena parte del espacio ocupado por la basura no quiere decir que estos niveles correspondan a vertederos de la población, entendiendo por ello como el lugar destinado a los desechos de toda o una parte de los pobladores. Un vertedero desde el punto de vista tafonómico producido por el hombre está definido por sus dimensiones como contenedor y por la densidad de ejemplares sacrificados y consumidos que se arrojaron en estos lugares en referencia a los depósitos naturales (Bernáldez, 2002b). Hemos estudiado la dinámica de formación de depósitos óseos en los actuales ecosistemas terrestres, pero aún estamos en una primera fase en el estudio de los concheros y otros depósitos de organismos marinos y terrestres del litoral onubense. Por ello, en este análisis discriminamos entre el depósito de las especies de vertebrados terrestres y el resto -vertebrados marinos y malacofauna-.

El contenido de vertebrados terrestres de este yacimiento no difiere mucho de lo que se viene registrando en la mayoría de los 50 yacimientos que hemos estudiado en el SO de Andalucía (Bernáldez, 1996a), donde más del $95 \%$ de la masa orgánica corresponde a los vertebrados terrestres con más de un $\mathrm{Kg}$ de masa corporal. Algo similar a lo que se observó en el estudio realizado sobre la formación de depósitos de huesos en la Reserva Biológica de Doñana que limitaba el hallazgo prácticamente a los vertebrados terrestres con más de un $\mathrm{Kg}$ de masa corporal, entre ellos existen diferencias en la representatividad de las especies con más de $50 \mathrm{Kg}$ y el resto. Del grupo primero están todas las especies presentes en la asociación de cadáveres, mientras que de las especies con menos de $50 \mathrm{Kg}$ apenas si hay restos de algunos de los carnívoros más pesados y de los lagomorfos, a pesar de ser las poblaciones más numerosas.

Por la coincidencia de los enclaves, tanto del yacimiento arqueológico como del estudio bioestratinómico de la misma reserva, podemos observar la naturaleza de ambos depósitos y comprobar si hay una dinámica de formación determinada por los distintos agentes que los generan y de las condiciones de conservación.

En primer lugar, tenemos que la variedad de especies conservadas en los tres cortes, en cuanto a vertebrados terrestres con más de un $\mathrm{Kg}$ de masa corporal, difiere poco entre ellos: encontramos vaca, caballo, cerdo/jabalí y caprinos, especies de ungulados con más de $25 \mathrm{Kg}$ de masa; tres especies de carnívoros, un perro, un meloncillo y un tercero por determinar; además de conejo, gallo y perdiz que son las especies más pequeñas de este grupo. Es evidente que frente a las 262 especies de vertebrados terrestres (excluyendo las 17 especies de anfibios y peces lacustres) que existen en los ecosistemas de Doñana (Ber- 
náldez, op.cit.), estas 10 especies, menos del $4 \%$ de las actualmente vivas, no representan a la comunidad actual ni, seguramente, a la paleocomunidad de entonces de la que los antiguos pobladores obtenían las proteínas animales suficientes en su alimentación. En la superficie de la actual Doñana el número de especies que podemos encontrar muertas sobre la superficie, bien representada por el cadáver completo o por un fragmento de hueso, no excede el $5 \%$ de las especies de vertebrados terrestres que habitan este ecosistema (excluidos los peces dulceacuícolas y los anfibios). En este porcentaje son los mamíferos con más de un $\mathrm{Kg}$ de masa los que componen el $70 \%$ de las especies, y de ellos sólo el grupo de los ungulados es el que está representado por todas sus especies, no olvidemos que los adultos son animales con más de $50 \mathrm{Kg}$ de masa corporal.

En esto coincide en un gran porcentaje con los yacimientos arqueológicos de cualquier época, la diferencia la hallamos en las especies, sobre todo de ungulados. Mientras que en los ecosistemas naturales los cadáveres proceden de especies silvestres, a menos que se introduzcan, como ocurre en el Parque Nacional de Doñana, algunas domesticadas como las vacas, las ovejas y las cabras; en las asociaciones de restos arqueológicos datados desde el Calcolítico hallamos básicamente las especies de ungulados actualmente domesticados, sin excluir algunas silvestres según la función (zonas rituales o zanjas de desechos ) de la estructura excavada y el ecosistema en el que está emplazado (sierra, valle, costa). Pues en este caso y en el yacimiento romano de El Eucaliptal (Bernáldez, 1996b), a pesar de la cercana fauna silvestre que debía existir, la asociación de vertebrados terrestres está formada por especies actualmente domesticadas, con una duda en cuanto a los suidos: en casi todos los niveles aparecen colmillos de machos adultos cuya forma y medida son similares a las de los jabalíes. En cualquier caso, no difiere de lo que venimos encontrando en cualquier yacimiento histórico donde hallamos vacas, cerdos/jabalíes y cabras como las especies más frecuentes, independientemente de las condiciones ambientales del enclave; en los que se repite con alta frecuencia la presencia de ciervos y conejos.

En el yacimiento de El Cerro del Trigo no hemos hallado restos de ciervos, por el contrario, se conservaban restos óseos de caballo que suelen ser poco frecuentes y aún lo es menos el estado de conservación que presentaban: tibias completas sin huellas de despiece; de lo que se deduce, siguiendo este criterio, que no fue sacrificado para el consumo. Entre los carnívoros hallamos restos de perro, un meloncillo y un tercer carnívoro, ninguno presenta huellas de despiece, además estos carnívoros silvestres se concentran en la unidad de ocupación romana del corte 6, en El Cerro de la Cebada. Entre las especies de aves, a pesar de ser las más abundantes en la comunidad y algunas de ellas tener una considerable masa corporal, que le permitiría una mejor conservación, sólo hay algunos huesos completos de gallina de pequeña envergadura -Gallus domesticus-y de perdiz -Alectoris rufa-.
Fig. 2. Contenido de cadáveres, Cerro del Trigo en Doñana. Las diferencias en la densidad de individuos en las distintas unidades pueden deberse a la diferencia de volumen excavado 0 a la naturaleza basurera del depósito

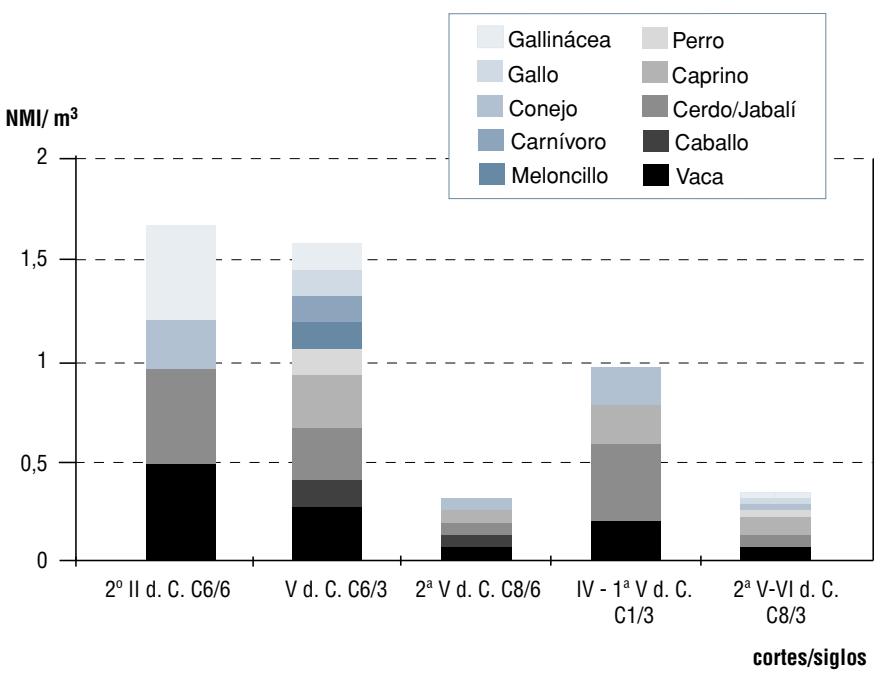

Fig. 3. Contenido de cadáveres, Cerro del Trigo en Doñana y El Eucaliptal en Punta Umbría. Estudio comparativo de la densidad de individuos conservados en las unidades excavadas en el yacimiento romano (IV d.C.) de El Eucaliptal en Punta Umbría

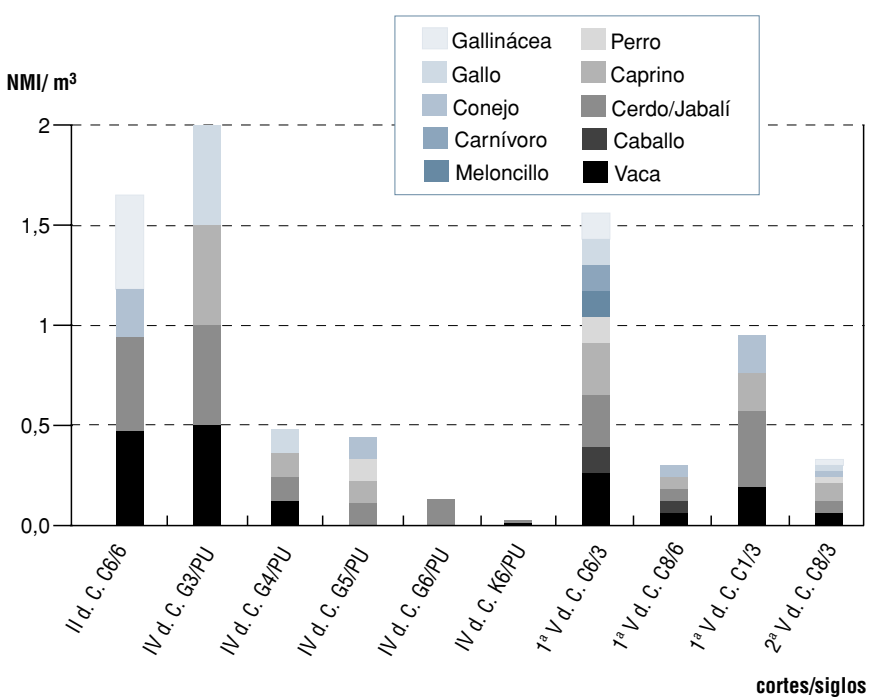

Fig. 4. Tamaño de las vacas a lo largo de la historia. Falanges I de las vacas consumidas en la Sevilla pre e histórica desde hace 8000 años en contraste con las actuales marismeñas de Doñana, con especial mención de las piezas encontradas en el yacimiento romano del Cerro del Trigo

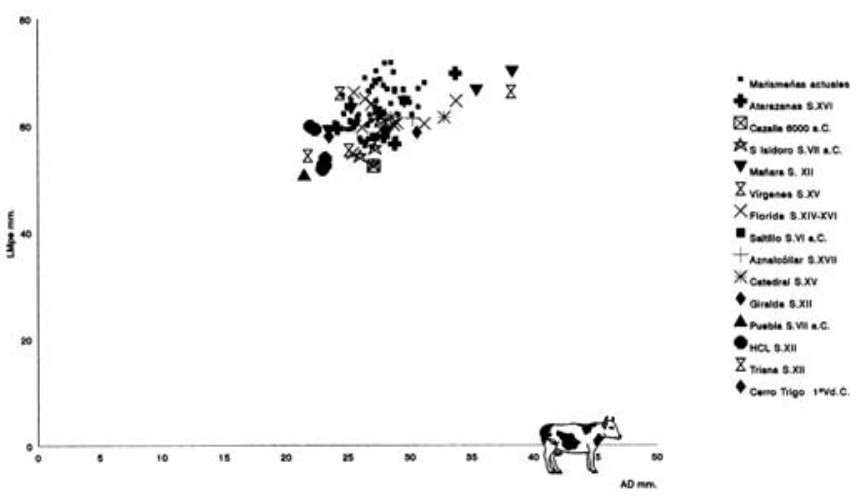


Fig. 5. Tamaño de los caprinos a lo largo de la historia. Falanges I de los caprinos de la Sevilla pre e histórica, en contraste con los ejemplares del yacimiento romano del Cerro del Trigo

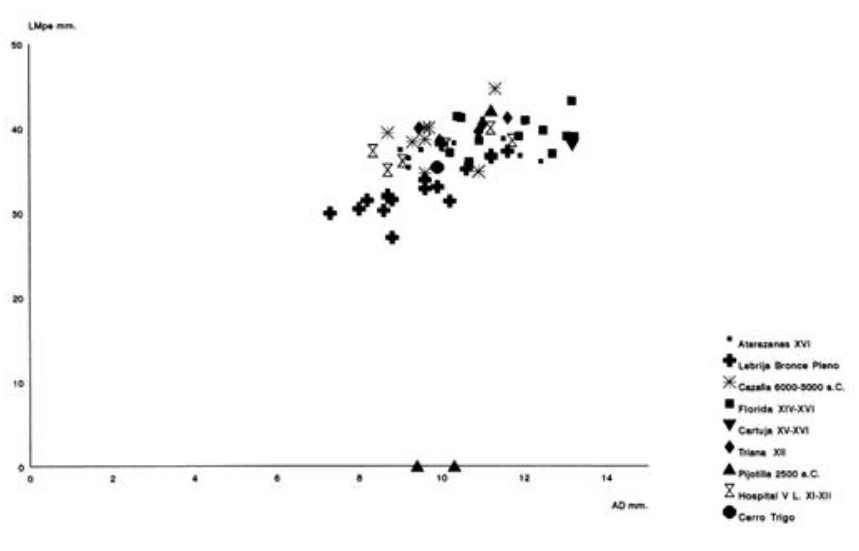

Fig. 6. Tamaño de los conejos a lo largo de la historia. Pelvis de conejos conservados en yacimientos de la ciudad y provincia de Sevilla con referencia a la población actual de Medina Sidonia en la Sierra de Cádiz. Se observa cómo los conejos del siglo XVI están más próximos a los actuales que los prehistóricos

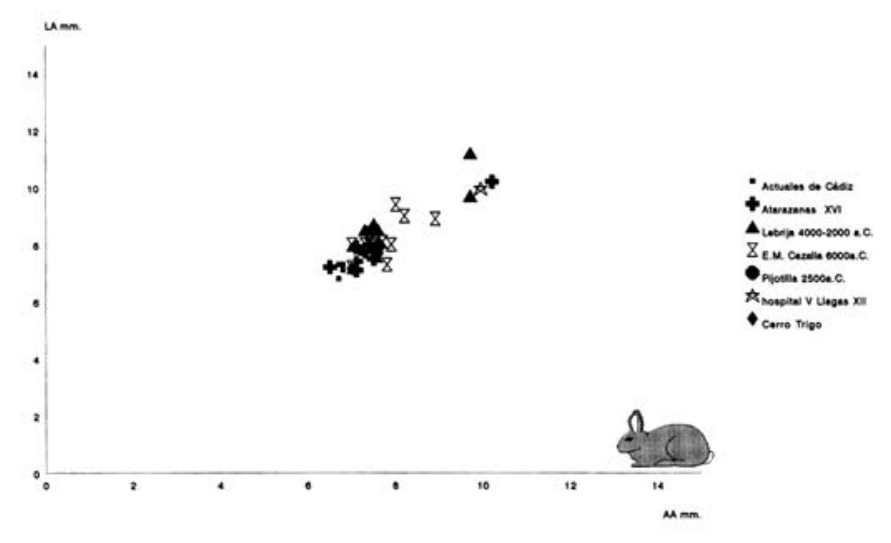

Fig. 7. Tamaño de los conejos a lo largo de la historia. Tibias de los conejos conservados en yacimientos de la ciudad y provincia de Sevilla desde el 6000 a.C. hasta la actualidad. La población actual corresponde a Medina Sidonia (Sierra de cádiz). Incluidos ejemplares del yacimiento romano del Cerro del Trigo

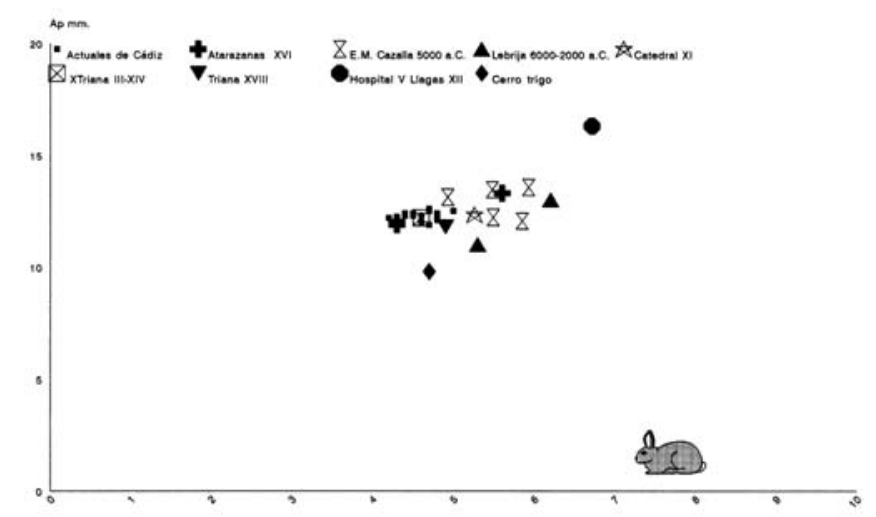

Los demás huesos rescatados corresponden a vertebrados marinos de teleósteos como atunes - Thunnus thynus-, corvinas -Argirosomus regius-y doradas -Sparus aurata-; y también se conserva alguna vértebra de seláceo -tiburón-, posiblemente de pintarroja-Scyliorhinus canicula-. En realidad, hallamos escasas especies de peces en comparación con la variedad ictiológica de estas costas; pero las conservadas aquí son muy significativas en la alimentación humana actual e histórica, según la documentación consultada (Apicio, Columela, Plinio). Por otra parte, hemos hallado una alta frecuencia relativa de mandíbulas de doradas en relación con la de cualquier otra parte anatómica de ésta y de las otras especies. Curiosamente encontramos una cita que hace referencia al ofrecimiento que en época romana se hacía de las cabezas de doradas a los dignatarios del puerto (Bauchot \& Pras, 1987), esto no quiere decir que sea la explicación a este hecho; ya que es la parte anatómica que mejor podemos identificar entre espinas y vértebras y la que con más frecuencia quedaría entre los desechos.

En cuanto a la cantidad de ejemplares sacrificados que se han conservado en estos depósitos tenemos que la densidad de ejemplares conservados en los cortes oscila entre 1.90 y 0.17 individuos $/ \mathrm{m}^{3}$, en cualquier caso unos valores superiores a los hallados en las condiciones naturales de la Reserva Biológica de Doñana donde el máximo registro fue de 0.06 ejemplares de vertebrados $/ \mathrm{m}^{3}$ debido esencialmente a la actividad carroñera. Unos valores que, a medida que superan el valor anterior para los ecosistemas silvestres, nos señalan la acumulación intencionada de basura orgánica cuyo agente tiene un comportamiento trófico selectivo y zootécnico, es decir, de manejo del tamaño de las especies consumidas. La presencia predominante de especies actualmente domesticadas, la densidad de ejemplares conservados -fig. 2-y el estado de conservación de los huesos son los indicadores biológicos de que el agente productor de la mayor parte de estos desechos es el hombre, lo que no implica que fuese el agente enterrador.

\section{LAS DIFERENCIAS EN EL CONTENIDO PALEOORGÁNICO DE LOS DEPÓSITOS}

Ya hemos mencionado la tendencia general del contenido paleoorgánico entre los cortes de este yacimiento y el de otros muchos yacimientos prehistóricos, protohistóricos e históricos de nuestra región respecto a la mostrada por el ecosistema natural de Doñana, sin contar con la intervención humana. Pero esta similitud a grandes rasgos tiene sus diferencias en cada depósito arqueológico del yacimiento del Cerro del Trigo. La primera de ella es la diferencia en el número de especies e individuos conservados que puede deberse a un mayor o menor uso de los depósitos, a un mejor o peor estado de conservación del basurero original o a la diferencia de volumen excavado en los tres cortes que vamos a estudiar, I, 6 y 8.

Para saber si estos depósitos fueron más o menos usados necesitamos los límites totales de los mismos y desconocemos este detalle, lo que implica que los datos tendrán un tratamiento analítico aplicado a las muestras. En cuanto al estado de conservación es obvio, que según el número de huesos conservados por individuo, medido por el índice de conservación esquelético ICEn, hay una gran pérdida de huesos de los 
individuos ya conservados. En ningún caso ha excedido el $3 \%$ del total de huesos del esqueleto de cada individuo; pero ignoramos si esta pérdida se debe a un tratamiento anterior del despiece que los humanos practicamos antes de consumir los animales sacrificados, a procesos predeposicionales superficiales y postdeposicionales que mermaron esa información o al tamaño de la muestra que estamos estudiando.

En cuanto a la importancia de los depósitos la estimamos a partir del volumen de éstos y de la cantidad de animales sacrificados arrojados aquí. Contando con vertebrados terrestres, tenemos que los cortes 6 y 8 , con 20 y 17 ejemplares de 10 y 7 especies respectivamente, son los que conservan mayor número de individuos y variedad de especies. En el corte 4 no hallamos restos de vertebrados terrestres y en el corte I se estimó que los restos pertenecían, al menos, a cinco individuos de cuatro especies. En primer lugar, diríamos que los depósitos 6 y 8 son los que contienen mayor número de ejemplares conservados, puesto que se reparten el $86.9 \%$ de los ejemplares de vertebrados terrestres, en el corte I sólo hallamos el $13.1 \%$ restante. Así que estos resultados determinarían como vertederos de mayor contenido a los cortes 6 y 8 sobre el corte I con el que comparamos y sobre el resto de los cortes que no registraron este tipo de material faunístico. Sin embargo, teniendo en cuenta el volumen excavado, la densidad de ejemplares encontrados nos muestra que son los cortes I y 6 los que contienen mayor cantidad de ejemplares por $\mathrm{m}^{3}$.

Según vemos en la tabla 2, la diferencia de animales conservados en cada unidad de cada corte y los volúmenes que ocupaban marcan una gran diferencia entre el corte 8 y los otros dos. Por ejemplo, la unidad 3 del corte 6 , que ocupa el $11.13 \%$ del volumen total de basura orgánica, registra 1.57 ejemplares por unidad de volumen procedentes de diez especies de vertebrados terrestres, por el contrario, el $49.4 \%$ de ese volumen procedente de la unidad 3 del corte 8 , conteniendo similar cantidad de individuos correspondiente a siete especies de vertebrados terrestres, registra una densidad de individuos por $\mathrm{m}^{3}$ de 0.33 . Lo que nos queda claro es que el corte 6 contiene la mayor variedad faunística y el mayor número de especímenes de forma absoluta y en referencia al volumen muestreado, un hecho que podría estar demostrando que el corte 6 es el vertedero más denso en desechos orgánicos; bien porque desde su origen fue un basurero al que se arrojó más basura o bien porque las condiciones de conservación fueron más estables que las de los otros dos cortes. Y el segundo punto que nos queda claro es que la densidad de ejemplares en la unidad 3 del corte I, que representa sólo el $7.77 \%$ del volumen con basura, es superior a las unidades del corte 8 y cercana a las del corte 6, lo que nos muestra a un vertedero de similar concentración de animales y de menor variedad de especies que las unidades de ocupación romana de los otros cortes.

Si observamos los resultados tenemos que en el corte I apenas hay un registro de animales que no sean los ungulados, los que tienen mayor probabilidad, por su tamaño, de conservación desde el punto de vista de la depredación y el carroñeo. Se conservan restos de vacas, cerdos y caprinos básicamente y aparece algún resto de conejo, un animal cuyo comportamiento excavador suele romper la estratigrafía original y dificultar su adscripción al nivel en el que se ha encontrado. No se conservan restos de caballos, de ungulados silvestres (corzos, cabras, muflones, gamos) que habitan los actuales ecosistemas ibéricos, ni de pequeños mamíferos (carnívoros, roedores) y aves. Podríamos decir que no aparecen las especies infrecuentes mayores de $50 \mathrm{Kg}$ y las de menor masa que no sean excavadoras. Así explicaríamos estas ausencias en función de los resultados bioestratinómicos obtenidos en Doñana. Podríamos suponer que a este lugar fueron a parar restos del consumo humano que arrojaron sobre la superficie, produciéndose una gran pérdida de huesos y pequeños cadáveres antes de su enterramiento en condiciones naturales.

Por el contrario, en los cortes 6 y 8 hallamos unidades, las de la ocupación romana, datadas en momentos distintos del siglo $V$ d.C. y en la primera mitad del siglo II d.C., que contienen huesos de pequeñas aves y carnívoros, cuyos estados de conservación se asemejan más al determinado en un ecosistema natural que al antrópico; donde los huesos enterrados están enteros y hasta conectados. En ambas unidades la mayor parte de esas pequeñas especies son silvestres en contraste con las de mayor masa que son especies actualmente domesticadas. Podríamos deducir de esas características tafonómicas más que una ampliación del espectro alimenticio, un doble origen de los registros faunísticos que tienen por agentes productores al hombre como responsable de la deposición de los ungulados (vacas, cerdos y caprinos) y a los agentes bióticos y abióticos (carroñeros, transporte de agua, dinámica de dunas) como los responsables de la conservación de pequeñas especies silvestres.

Observando los resultados en el corte 8 , tenemos que la densidad de vertebrados terrestres entre ambas unidades de ocupación (3 y 6) muestra la misma proporción que el volumen excavado. De manera que a doble volumen tenemos doble densidad de individuos, de lo que deducimos que la unidad más antigua, de la segunda mitad del siglo $\vee$ d.C., es la mitad de densa en ejemplares sacrificados que la siguiente, datada a finales de esa segunda mitad e inicios del siglo VI d.C. Dicho efecto puede tener como causa el mayor uso del basurero o su mejor conservación a lo largo del tiempo. Una razón, esta última, que podría explicar la ausencia de caprinos y demás especies de menor masa corporal, al igual que explicamos las condiciones tafonómicas de la unidad de ocupación romana del corte I.

Como tenemos la duda del efecto que puede producir el aumento de volumen de las muestras, compararemos dos grupos de unidades en función del volumen ocupado: aquéllas que contienen menos de 8 $\mathrm{m}^{3}$ y las de mayor volumen. Así que el estudio comparativo se dará entre las unidades de cada grupo, por una parte están las dos unidades del corte 6 y la del corte I, y por otra parte, las dos unidades del 


눔

corte 8. En el primer caso, la densidad de ungulados en las dos unidades de ocupación del corte 6 es similar, 0.92 y 0.95, y muy próxima a la unidad de ocupación romana del corte I, 0.75. A pesar de que la variedad de especies es menor en el nivel más antiguo del corte 6 y aún más en el corte I, cuyo efecto más inmediato se nota en la diferencia de densidad de vertebrados terrestres, 0.94 en el corte I, I.54 en el nivel 3 del corte 6 y 1.90 en el nivel 6 del corte 6 . Es el caso contrario al hallado entre los niveles de ocupación del corte 8, cuya unidad más antigua, de la segunda mitad del siglo $\vee$ d.C., contiene menor densidad y variedad de especies que en la producida al final de ese mismo siglo.

De estos resultados interpretamos que la mayor densidad de basura orgánica, medida por los ejemplares sacrificados aquí conservados y la variedad faunística, se registra en la unidad de ocupación datada en la primera mitad del siglo II d.C., una densidad que posiblemente aumentaría si el volumen de la muestra hubiese sido mayor, ya que no tenemos todas las especies comunes de ungulados esperadas,

\begin{tabular}{|c|c|c|c|c|c|c|c|c|c|c|}
\hline NMI/DI & $\begin{array}{c}\mathrm{C} 1 / 3 \\
5.32 \\
\mathrm{~m}^{3}\end{array}$ & $C 4 / 3$ & $\begin{array}{c}\mathrm{C} 6 / 3 \\
7.62 \\
\mathrm{~m}^{3}\end{array}$ & $\begin{array}{c}\mathrm{C} 6 / 6 \\
4.22 \\
\mathrm{~m}^{3}\end{array}$ & $\begin{array}{c}\mathrm{C} 6 / 10 \\
0.032 \\
\mathrm{~m}^{3}\end{array}$ & $\begin{array}{c}\mathrm{C} 6 / 12 \\
0.041 \\
\mathrm{~m}^{3}\end{array}$ & $\begin{array}{c}\mathrm{C} 6 / 13 \\
0.11 \\
\mathrm{~m}^{3}\end{array}$ & $\begin{array}{c}\mathrm{C} 8 / 3 \\
33.81 \\
\mathrm{~m}^{3}\end{array}$ & $\begin{array}{c}\mathrm{C} 8 / 6 \\
17.47 \\
\mathrm{~m}^{3}\end{array}$ & $\mathrm{C} 8 / 11$ \\
\hline $\mathrm{Bt}$ & $1 / 0.19$ & 0 & $2 / 0.26$ & $2 / 0.47$ & 0 & 0 & 0 & $2 / 0.06$ & $1 / 0.06$ & 1 \\
\hline $\mathrm{Ec}$ & 0 & 0 & $1 / 0.13$ & 0 & 0 & 0 & 0 & 0 & $1 / 0.06$ & 0 \\
\hline Ss & 2/0.38 & 0 & $2 / 0.26$ & $2 / 0.47$ & 0 & 0 & 0 & $2 / 0.06$ & $1 / 0.06$ & 1 \\
\hline Cap & $1 / 0.19$ & 0 & $2 / 0.26$ & 0 & 0 & 0 & 0 & $3 / 0.09$ & 0 & 1 \\
\hline UNG & $4 / 0.75$ & 0 & $7 / 0.92$ & $4 / 0.95$ & 0 & 0 & 0 & $7 / 0.21$ & $3 / 0.17$ & 3 \\
\hline $\mathrm{Cf}$ & & & $1 / 0.13$ & & & & & $1 / 0.06$ & & \\
\hline $\mathrm{Hi}$ & & & $1 / 0.13$ & & & & & & & \\
\hline Car & & & $1 / 0.13$ & & & & & & & \\
\hline $0 c$ & $1 / 0.19$ & & & $1 / 0.24$ & & & & $1 / 0.06$ & & 1 \\
\hline $\mathrm{Gd}$ & & & $1 / 0.13$ & & & & & $1 / 0.06$ & & \\
\hline $\mathrm{Ar}$ & & & $1 / 0.13$ & $2 / 0.47$ & & & & & & \\
\hline VER & $5 / 0.94$ & 0 & $12 / 1.57$ & $7 / 1.66$ & & & & $10 / 0.30$ & $3 / 0.17$ & 4 \\
\hline peces & $\mathrm{Ag}$ & & $\mathrm{Sa}$, Tel & Tel & & & & Tt,7SaTel & I Tt & $\mathrm{Ag}$ \\
\hline $\begin{array}{l}\text { mala- } \\
\text { cofauna }\end{array}$ & Gly-Oe & $\begin{array}{l}\text { Gly + } \\
\text { 2spp }\end{array}$ & $\begin{array}{c}\text { Gly-0e+ } \\
12 \text { spp }\end{array}$ & $\begin{array}{l}\text { Gly-0e+ } \\
6 \mathrm{spp}\end{array}$ & $\begin{array}{c}\text { Gly-Oe+ } \\
1 \text { spp }\end{array}$ & Gly & Gly & $\begin{array}{l}\text { Gly-0e+ } \\
6 \text { spp }\end{array}$ & $\begin{array}{c}\text { Gly-Oe+ } \\
1 \text { sp }\end{array}$ & $\begin{array}{l}\text { Gly-Oe+ } \\
2 \text { spp }\end{array}$ \\
\hline & $\begin{array}{l}\text { final } \\
\text { IV- } 1^{a} V d . C .\end{array}$ & & Vd.C. & $1^{\text {allid.C. }}$ & & & & $\begin{array}{l}2^{\text {aV}} \text {-inicio } \\
\text { VId.C. }\end{array}$ & $2^{\text {a Vd.C. }}$ & \\
\hline
\end{tabular}

Se indica el número mínimo de individuos de vertebrados terrestres y marinos (peces) -NMI- y la densidad de ejemplares de vertebrados terrestres -DI-. Bt: Bos taurus -vaca-; Ec: Equus caballus -caballo-; Ss: Sus scrofa -cerdo-jabalí-; Cap: caprinos Ovis aries y Capra hircus -oveja y cabra-; UNG.: ungulados; Cf: Canis familiaris - perro-; Cf*: Canis familiaris o lupus -perro o lobo-; Hi: Herpeste ichneumon -meloncillo-; Car: carnívoro de media talla; Oc: Oryctolagus cuniculus -conejo-; Gd:Gallus domesticus -gallina-; Ar: Alectoris rufa- perdiz. VER.: vertebrados terrestres. Incluye los peces Ag: Argirosomus regius - corvina-; Tt: Thunnus thynnus -atún-; Sa: Sparus aurata -dorada-; Tel: teleósteo. Los invertebrados hallados corresponden a moluscos de las especies Gly: Glycymeris glycymeris -almendra de mar-; Oe: Ostrea edulis - ostra- y hasta 20 especies más de moluscos. Finalmente, añadimos el volumen de los depósitos y la datación de los mismos. bien porque sus huesos son los más frágiles debido al tamaño de los individuos como en el caso de los caprinos, bien por un escaso número de ejemplares de la población natural como en los caballos, sin descartar que su escasez fuese debida al poder adquisitivo de sus pobladores. El resto de las unidades con desechos paleoorgánicos responden a basureros formados en distintos momentos del siglo $V \mathrm{~d}$.C., por una parte encontramos que hay un gradiente en la densidad de ejemplares y de especies entre las unidades de ocupación del corte 8, datadas en la segunda mitad del siglo $\vee$ d.C. $y$ finales de éste e inicios del VI, de manera que aumenta dicha densidad a lo largo del tiempo en la unidad más moderna. La presencia de una tibia derecha completa en el nivel 3 del corte 8 y otra de iguales dimensiones y del lado izquierdo en el nivel 3 del corte 6 hace sospechar que es de un único animal, pero en ese caso ambos depósitos formarían parte de un sólo vertedero y de la misma época, aún cuando sus dataciones difieren en algunas decenas de años (primera y segunda mitad del siglo $\vee$ d.C.).

Desde el punto de vista estratigráfico tenemos que el primer basurero tuvo su origen a principios del siglo ॥ d.C. en el lugar que denominamos El Cerro de la Cebada, unidad 6 del corte 6 . No hubo una sucesión temporal del mismo o fue arrasado para ser ocupado con otras funciones para el poblado, porque el nivel inmediatamente superior está datado en el siglo $\vee$ d.C., donde estimamos una densidad de ejemplares menor a la unidad anterior debida a la incorporación de especies silvestres de pequeños carnívoros que indican un posible doble origen del depósito, antrópico y natural, y ambos superficiales. A partir de aquí tenemos un nivel de arenas que cubrió todo indicio de ocupación humana. En el corte 8, en la Casa del Guarda, registramos dos unidades que muestran una sucesión temporal durante el siglo $\vee$ d.C. e inicios del VI, donde percibimos un aumento de las especies y de los individuos registrados en la unidad más moderna; pero nada en siglos anteriores y posteriores. Por último, el tercer basurero lo hallamos en la unidad de ocupación del corte I, más antiguo que las unidades del corte 8 , de finales del siglo IV e inicios del $V$ d.C., aquí tenemos una escasa representación de las especies silvestres, muy similar a la hallada para ungulados actualmente domesticados, posiblemente esta escasez de especies pequeñas nos esté indicando una pérdida de cadáveres debida al carroñeo o a la limpieza del sitio.

\section{CABALLOS EN LOS BASUREROS}

Ya se ha mencionado que la presencia de équidos en los yacimientos no suele ser frecuente, sin embargo, en este yacimiento encontramos tres tibias completas de un ejemplar en la unidad 3 del corte 6 y otro en la unidad 6 del corte 8; es decir, en el siglo $\vee$ d.C. $Y$ es extraño este hecho porque, no siendo un animal frecuente en el registro paleobiológico, aparece en dos lugares y en dos momentos, sobre todo en uno de los niveles con menos registro como es el de 
la unidad 6 del corte 8 . No hay huellas de despiece sobre la superficie del hueso, de lo que se deduce que no fue sacrificado para el consumo, lo que nos hace pensar en la muerte natural del animal que bien fue enterrado o arrojado a este sitio. Si fue enterrado, no encontramos explicación alguna de por qué no está el resto del animal, al menos en el corte 8 donde sus más de $33 \mathrm{~m}^{3}$ proporciona un volumen al descubierto sobradamente grande. Así que debía ser arrojado sobre la superficie, experimentando los procesos predeposicionales que se dan en un ecosistema, con la consiguiente pérdida de huesos. Hasta un $70 \%$ de ellos desaparecen en el transcurso de un año en las condiciones ambientales de la Reserva Biológica de Doñana (Bernáldez, 1996a). Pero debió ser una superficie bien cubierta de árboles porque no parece que la superficie de las tibias encontradas haya experimentado una exposición al sol extrema, como la detectada en esa reserva.

La presencia de este animal no es lo que llama nuestra atención, sino su ausencia en otros niveles. Las especies de ungulados presentes en una comunidad silvestre están todas representadas en la tanatocenosis - asociación de cadáveres- y en la tafocenosis -asociación de entidades enterradas-, cuando no hallamos restos de estos ungulados es o porque no forman parte de los recursos alimenticios del poblado o porque esa especie no vive en ese ecosistema, también podemos considerar su escasez que tiene como consecuencia la baja frecuencia de estar en el registro fósil.

Bajo el mismo criterio concluimos que la ausencia de ungulados silvestres como el ciervo, el corzo o el gamo, que bien podrían habitar estas tierras, está justificada en las preferencias del consumo humano por las vacas, los cerdos, los caprinos y las gallinas o/y en la prohibición de su caza. La presencia y ausencia de otras especies de menor masa corporal no justifican su consumo, puesto que de los carnívoros silvestres se conservan piezas anatómicas como falanges y cráneos que suelen ser las que hallamos en ecosistemas naturales, sin huellas de cortes, producto de la actividad carroñera en superficie; mientras que la presencia de conejos está relacionada con el comportamiento excavador que le permite irrumpir en estos niveles, menos en el caso de la unidad 6 del corte 6 en cuyo ejemplar observamos un corte de carnicería que le señala como producto del consumo humano.

\section{VACAS, CERDOS Y CABRAS}

Del contenido orgánico analizado nos queda determinar algunas de las características biológicas de los individuos enterrados cuyo número no es suficiente para inferir los resultados a la población existente. En la figura 4 aparecen las medidas de dos falanges I de uno o dos bóvidos conservados en la unidad 3 del corte 6, una unidad datada entre finales del siglo IV y la primera mitad del siglo $\vee$ d.C. El tamaño del ejemplar o ejemplares cuando fue sacrificado era inferior al promedio de las vacas retintas de la actual Doñana
Fig. 8. Tamaño de valvas derechas de Glicimeris glicimeris. Cerro del Trigo. Las valvas derechas de longitud $\mathrm{mm}$. Las almendras de mar parecen proceder de una selección en favor de las más grandes con escasa representatividad de los individuos más jóvenes

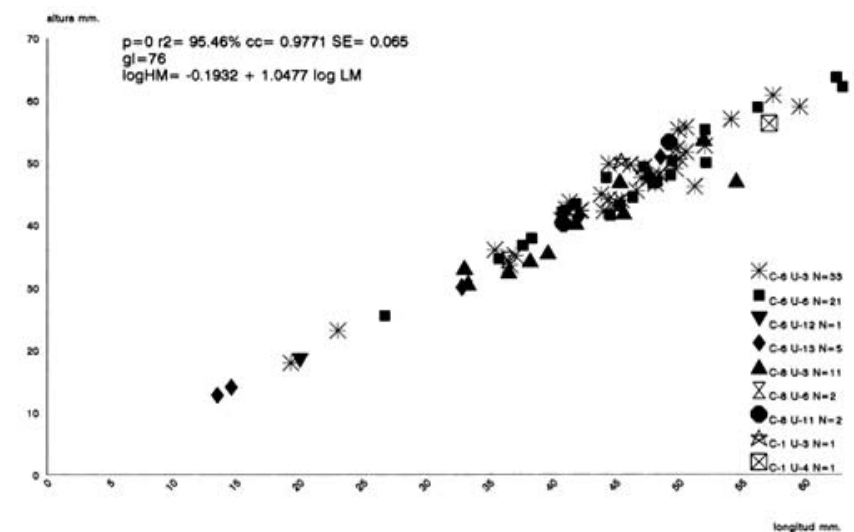

Fig. 9. Tamaño de valvas izquierdas de Glicimeris glicimeris. Cerro del Trigo. Entre las valvas izquierdas de almendras de mar se da la misma dinámica de conservación que en las derechas. Hay una selección en favor de las de mayor tamaño

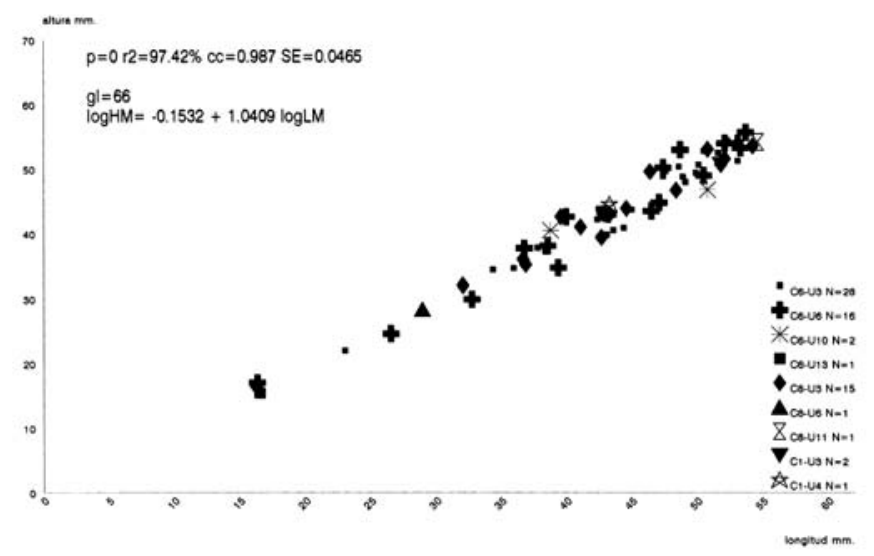

y de los hallados en los yacimientos mencionados en la gráfica datados con posterioridad al siglo $\mathrm{XV}$, aunque similar a los ejemplares hallados en los yacimientos arqueológicos de fechas anteriores.

Las medidas tomadas al único radio de cerdo encontrado en la unidad 6 del corte 6 , de la primera mitad del siglo II d.C., con una anchura mínima de la diáfisis de $17.1 \mathrm{~mm}$, responde a un individuo de talla media como los que venimos encontrando en esos mismos yacimientos.

La única falange I de caprino hallada en la unidad 3 del corte 6, datada en el siglo $V$ d.C., corresponde a un animal de talla intermedia entre las cabras del calcolítico de Lebrija -Fig. 5- y las que venimos encontrando en los yacimientos de datación posterior.

En los tres casos no podemos concluir más que: el sacrificio de estos tres individuos ocurrió antes de finalizar su madurez, según hemos observado en la fusión más o menos reciente de diáfisis y epííisis de los huesos largos, que en los ungulados suele ser a los cuatro años, una edad que aún hoy es la seleccionada en los mataderos de especies retintas. 


$\longleftarrow$
$\square$

En el caso del conejo no podemos determinar si es un ejemplar domesticado o no, puesto que el tamaño no excede la media estimada para la población actual silvestre de estos lagomorfos. El tamaño de la pelvis encontrada en la unidad 3 del corte 8 así lo demuestra -fig. 6-; mientras que el tamaño del ejemplar hallado en la unidad 3 del corte I es inferior al de la muestra estudiada para la Sierra de Cádiz; la tibia hallada es, probablemente, de un subadulto -fig. 7-.

\section{EL EUCALIPTAL V.S. CERRO DEL TRIGO: ASENTAMIENTOS ROMANOS EN LA COSTA ONUBENSE}

En la playa onubense de Punta Umbría se excavó el yacimiento romano del siglo IV d.C. de El Eucaliptal en

Tabla 3. Número mínimo de individuos de vertebrados terrestres -NMI- conservados en los cortes realizados en el yacimiento romano del siglo IV a.C. de El Eucaliptal situado en Punta Umbría -costa de Huelva-; añadimos el volumen de cada depósito y la presencia de ictiofauna y el número de especies de moluscos con predominancia de almendras de mar -gly-, navajas-sol- , especies de la púrpura -pury ostras - ost-

\begin{tabular}{|c|c|c|c|c|c|c|c|c|c|c|c|c|c|c|c|}
\hline NMI & E2 & E4 & E5 & E6 & F1 & F4 & G3 & G4 & G5 & G6 & 11 & 12 & 13 & K2 & K6 \\
\hline Bt & 0 & 1 & 1 & 1 & 1 & 1 & 1 & 0 & 0 & 0 & 1 & 1 & 1 & 1 & 1 \\
\hline Ss & 0 & 1 & 0 & 0 & 0 & 0 & 1 & 1 & 1 & 0 & 1 & 0 & 1 & 0 & 1 \\
\hline $\mathrm{Ca}$ & 1 & 0 & 1 & 0 & 1 & 1 & 1 & 1 & 1 & 1 & 1 & 1 & 3 & 0 & 0 \\
\hline UN & 1 & 2 & 2 & 1 & 2 & 2 & 3 & 2 & 2 & 1 & 3 & 2 & 5 & 1 & 2 \\
\hline Cf & & & & & & & & & 1 & & & & & & \\
\hline $0 c$ & & & & & & & & & 1 & & & & & & \\
\hline$\underline{\mathrm{Gd}}$ & & & & & & & 1 & 1 & & AV. & & 1 & & & \\
\hline VER & 1 & 2 & 2 & 1 & 2 & 2 & 4 & 3 & 4 & 2 & 3 & 3 & 5 & 1 & 2 \\
\hline pec. & & & & & & & Sa & $\mathrm{Ln}$ & & & & & $\mathrm{Ln}$ & & \\
\hline $\mathrm{mol}$ & & & & & & gly & sol-gly & sol-ost & gly & pur & & & pur & & gly \\
\hline NSP & 2 & 3 & 7 & 2 & & 7 & 11 & 4 & 8 & 5 & & & 2 & & 5 \\
\hline vol & 1.87 & 28.8 & 8.75 & 4 & 3.78 & 3.2 & 2 & 8.4 & 8.8 & 8 & 3.84 & 2.24 & 10.5 & 3.15 & 72 \\
\hline
\end{tabular}

Tabla 4. Densidad de individuos -DI- de vertebrados terrestres conservados en los cortes realizados en el yacimiento romano del siglo IV d.C. de El Eucaliptal en Punta Umbría -costa de Huelva-. UN: ungulados; VE: vertebrados

\begin{tabular}{|c|c|c|c|c|c|c|c|c|c|c|c|c|c|c|c|}
\hline 1 & E2 & E4 & E5 & E6 & $\mathrm{FI}$ & F4 & G3 & G4 & G5 & G6 & 11 & 12 & 13 & $\mathrm{~K} 2$ & K6 \\
\hline Bt & 0 & 0.03 & 0.11 & 0.25 & 0.26 & 0.32 & 0.5 & 0 & 0 & 0 & 0.26 & 0.45 & 0.1 & 0.32 & 0.01 \\
\hline & 0 & 0.03 & 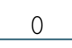 & 0 & 0 & 0 & 0.5 & 0.12 & 0.11 & 0 & 0.26 & 0 & 0.1 & 0 & 0.01 \\
\hline a & 0.53 & 0 & 0.11 & 0 & 0.26 & 0.32 & 0.5 & 0.12 & 0.11 & 0.13 & 0.26 & 0.45 & 0.29 & 0 & 0 \\
\hline IN & 0.53 & 0.07 & 0.23 & 0.25 & 0.53 & 0.63 & 1.5 & 0.24 & 0.23 & 0.13 & 0.78 & 0.89 & 0.48 & 0.32 & 0.03 \\
\hline if & & & & & & & & & 0.11 & & & & & & \\
\hline De & & & & & & & & & 0.11 & & & & & & \\
\hline 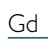 & & & & & & & 0.5 & 0.12 & & 0.13 & 0.4 & & & & \\
\hline & 0.53 & 0.07 & 0.23 & 0.25 & 0.53 & 0.63 & 2 & 0.36 & 0.45 & 0.25 & 0.78 & 1.34 & 0.48 & 0.32 & 0.03 \\
\hline
\end{tabular}

1993 por el mismo equipo de arqueólogos de la Universidad de Huelva (Campos et all., 1999). La variedad faunística, el número mínimo de individuos y la densidad de los mismos correspondientes a cada especie registrada en cada corte han sido las variables que hemos comparado para concluir que la diferencia, en cuanto a las especies registradas en ambos yacimientos se encuentra en la unidad 3 del corte 6 (siglo $\checkmark$ d.C.). El resto de las unidades y cortes del yacimiento de El Cerro del Trigo y de El Eucaliptal presentan una tendencia similar a conservar las tres especies de ungulados actualmente domesticadas de mayor frecuencia en cualquier yacimiento antrópico: vacas, cerdos y caprinos. Seguido por pollos, conejos y perros a los que se les ha añadido, de manera esporádica, alguna que otra especie silvestre -la perdiz, el meloncillo y otro pequeño carnívoro-.

Esta similitud en la variedad faunística se repite en el número de ejemplares que venimos hallando en las excavaciones, número que oscila entre uno y tres ejemplares, algo escaso para extrapolar los resultados a una reconstrucción cuantitativa de las preferencias alimenticias, pero suficiente para determinar la importancia de los depósitos en su función de basureros intencionados.

En las Tablas 2, 3 y 4 tenemos que la densidad de ejemplares de los cortes practicados en uno y otro yacimiento proceden de depósitos con dimensiones distintas, como ya hemos hecho anteriormente, la interpretación dependerá de la variable que defina la densidad del contenido, es decir, de la cantidad de ejemplares que se arrojaron o se conservaron por unidad de volumen, y de las dimensiones del depósito.

En la figura 3 se recoge la variedad faunística y la densidad de individuos, siendo obvio que a menor volumen del depósito mayor es la densidad de ejemplares, aunque no el número de especies.

Tenemos una cuestión que resolver antes de deducir el estado de conservación de estos depósitos: la distribución de los restos en los cortes. Un dato que desconocemos y que es básico porque la distribución en agregado o concentrada responde a basureros inmersos en estructuras arqueológicas y la distribución azarosa nos indica bien una nula intencionalidad de formar un basurero o que toda la capacidad de la estructura arqueológica ha sido utilizada, después de su abandono, como contenedor. Es decir, las directrices de la excavación va siempre en función de los hallazgos arqueológicos, sobre todo, de las construcciones, de modo que el volumen excavado suele ir en función de este tipo de hallazgo; el material orgánico aquí asociado carece, en muchas ocasiones, de datos sobre su distribución y volumen real ocupado, en consecuencia desconocemos la verdadera concentración de individuos. En los cortes en estudio carecemos de esta información para discriminar entre el material óseo distribuido azarosamente y el concentrado en determinadas estructuras.

Si consideramos que ese material tenía una distribución azarosa en las unidades excavadas, concluiríamos 
que todos presentan una densidad de individuos superior a la registrada para un ecosistema natural, pero la mayoría tiene unos valores muy próximos a éste; exceptuando los más concentrados como son las unidades de los cortes I y 6 y el corte G-3 de El Eucaliptal. Lo primero nos sugiere que estas concentraciones de basura responden al despojo humano que muy posiblemente dejó sobre la superficie, enterrándose posteriormente en la misma proporción de huesos que se viene enterrando en los dos únicos lugares donde se ha realizado este tipo de estudio, en la Reserva Biológica de Doñana y en el Parque Nacional de Amboseli en Kenia (Behrensmeyer y Boaz, 1980).

Hay otro método para interpretar la conservación de estos depósitos y los posibles procesos que han intervenido en su origen: la malacofauna encontrada es relativamente frecuente, aunque no muy variada como ocurre con las especies de vertebrados.

\section{LA ASOCIACIÓN MALACOLÓGICA DE LOS YACIMIENTOS ROMANOS}

En un total de 294 elementos -valvas y caracolesprocedentes de 22 especies de moluscos, conservados en los cortes I, 4, 6 y 8, había un 74.8\% de almendras de mar-Glycimeris glycimeris-. El resto se reparte en porcentajes inferiores al $5 \%$ entre las restantes 22 especies, siendo las ostras la especie más frecuente con el 5.1\%. Esta cantidad fue recogida en un volumen excavado con elementos orgánicos de $79.12 \mathrm{~m}^{3}$, por lo tanto, la densidad de ejemplares invertebrados es de 3.72 por unidad de volumen.

En el yacimiento romano de El Eucaliptal se rescataron 458 elementos de 21 especies de moluscos, de ellos el $38.4 \%$ corresponde a las especies de la púrpura, básicamente a la cañaílla -Murex brandaris-, a Trunculariopsis trunculus y a Hexaplex sp; el $21.4 \%$ a las almendras de mar; el $17.2 \%$ a las ostras-Ostra edule-, el $14 \%$ a las navajas y el resto son representaciones mínimas. Los $224.72 \mathrm{~m}^{3}$ de volumen con restos orgánicos nos da una densidad media de 2.04 invertebrados por unidad de volumen.

Lo primero que nos llama la atención es la similitud en las cantidades de valvas, especies y volumen de los cortes que hacen que los valores de densidad de moluscos sea tan próximos. En cuanto a que el número de especies es también casi el mismo, no todas ellas se repiten en ambos yacimientos, coinciden en 14 de esas especies. La diferencia está en la proporción: mientras que en el Cerro del Trigo la presencia mayoritaria es de almendras de mar, en El Eucaliptal hay un grupo de cinco especies que componen el 91 $\%$ de los moluscos, las tres especies de la púrpura, las almendras de mar, las ostras y las navajas. El origen de ambos yacimientos, desde la variedad malacológica, podría explicarse desde la naturaleza de los concheros naturales o desde la actividad selectiva del hombre, debido a que son las especies más abun- dantes en las playas y también forman parte del consumo y uso humano. Necesitamos realizar un estudio bioestratinómico de los concheros situados en distintos puntos de la costa onubense para afirmar que son o no concheros de origen antrópico. Lo que sí es cierto es que la presencia de las especies de la púrpura sí es debida al hombre: la mayoría tiene un tamaño óptimo de consumo, aparecen casi todas machacadas y en una sola zona de El Eucaliptal, en los cortes I y 3 del sector I. Si eliminamos este grupo, entonces son las almendras de mar junto con las ostras y las navajas las especies predominantes, al igual que en El Cerro del Trigo.

Si analizamos la distribución del resto de las especies vemos que las almendras de mar están presentes en todos los cortes de ambos yacimientos, en El Cerro del Trigo siempre lo está junto a ostras, al igual que las hallamos en Punta Umbría, peregrinas y navajas, sobre todo, cuando es suficientemente representativa la muestra. De manera que ambos yacimientos responden a una zona de almendras de mar, ostras y peregrinas con navajas que podría estar asociada a las actividades humanas o a las condiciones tafonómicas de la misma playa.

Intentamos un segundo análisis de las condiciones biológicas de la especie más frecuente, las almendras de mar, con la intención de determinar el agente productor. Usualmente si estos desechos son producto de la recolección, la mayor parte de las valvas corresponden a una determinada clase de tamaño, ésta es, al menos, la premisa que se viene utilizando y es la que usaremos en este trabajo. Pero hemos de aclarar que nuestros últimos trabajos bioestratinómicos so-

Tabla 5. Estadística descriptiva de las medidas de longitud $-\mathrm{LM}-\mathrm{y}$ altura $-\mathrm{HM}$ - tomadas a las valvas derechas -D- e izquierdas - - - de las almendras de mar halladas en los yacimientos romanos de Cerro del Trigo en Almonte -CDT-y de El Eucaliptal en Punta Umbría -EPU- situados en la costa onubense

\begin{tabular}{lcccccc}
\hline & LMDCDT & HMDCDT & LMICDT & HMICDT & LMDEPU & LMIEPU \\
\hline $\mathrm{N}$ & 77 & 77 & 67 & 67 & 48 & 30 \\
\hline $\mathrm{x}$ & 43.828 & 43.418 & 43.265 & 43.42 & 54.063 & 45.367 \\
\hline mediana & 45.3 & 44.3 & 44.5 & 43.8 & 45.5 & 44 \\
\hline moda & 41 & 41.2 & 47.3 & 42.6 & 45 & 42 \\
\hline med.geo. & 42.414 & 41.808 & 41.957 & 41.946 & 51.427 & 45.101 \\
\hline varianza & 93.795 & 106.55 & 86.512 & 100.352 & 359.124 & 27.275 \\
\hline s.d. & 9.685 & 10.322 & 9.301 & 10.018 & 18.951 & 5.223 \\
\hline s.e. & 1.104 & 1.176 & 1.136 & 1.224 & 2.745 & 0.953 \\
\hline mínimo & 13.5 & 12.7 & 16.22 & 15.4 & 30 & 38 \\
\hline máximo & 62.9 & 63.6 & 59.4 & 63.6 & 100 & 60 \\
\hline rango & 49.4 & 50.9 & 43.18 & 48.2 & 70 & 22 \\
\hline n.s. & 0 & 0 & 0 & 0 & 0 & 0 \\
\hline g.l. & 76 & 76 & 66 & 66 & 47 & 29 \\
\hline t-Student & 39.711 & 36.910 & 38.075 & 35.478 & 19.765 & 48.043 \\
\hline & & & & & &
\end{tabular}




$\longleftarrow$
$\square$
$\square$

bre la conservación de caracoles terrestres en ecosistemas naturales pone seriamente en duda tal premisa, ya que los agentes naturales también favorece la conservación de los elementos más resistentes, de modo, que las pequeñas conchas suelen desaparecer mecánica o químicamente -por rotura o disolución-. A esta medida añadiremos una condición más: el tipo de distribución de las valvas en estos depósitos, si las encontramos esparcidas o agrupadas en los niveles excavados y si están junto a otros desechos cuyo origen antrópico no se preste a la menor duda, e.g.: huesos con corte de carnicería correspondientes a especies actualmente domesticadas.

Tabla 6. Número de valvas derechas - $\mathrm{d}-\mathrm{e}$ izquierdas $-\mathrm{i}-$ de almendras de mar $-\mathrm{N}-$ distribuidas en las distintas clases de tamaño expresado por la longitud en $\mathrm{cm}$ halladas en las distintas unidades de cada corte excavado -C- en el Cerro del Trigo -Almonte-. Añadimos el volumen de cada unidad para indicar el tamaño de las muestras -vol. m3-

\begin{tabular}{|c|c|c|c|c|c|c|c|c|c|c|}
\hline $\begin{array}{l}\mathrm{LM} \\
\mathrm{cm} / \mathrm{N}\end{array}$ & $\mathrm{C} 1 / 3$ & $\mathrm{C} 1 / 4$ & $\mathrm{C} 6 / 3$ & $\mathrm{C} 6 / 6$ & $\mathrm{C} 6 / 10$ & $\mathrm{C} 6 / 12$ & $\mathrm{C} 6 / 13$ & $\mathrm{C} 8 / 3$ & $\mathrm{C} 8 / 6$ & C8/11 \\
\hline $0-2 / 7$ & & & $1 d$ & $1 \mathrm{i}$ & & $1 d$ & $2 \mathrm{~d}-1 \mathrm{i}$ & $1 \mathrm{i}$ & & \\
\hline $2-4 / 33$ & & & $4 \mathrm{~d}-6 \mathrm{i}$ & $4 d-6 i$ & $1 \mathrm{i}$ & & $1 d$ & $5 \mathrm{~d}-4 \mathrm{i}$ & $1 \mathrm{~d}-1 \mathrm{i}$ & \\
\hline $4-6 / 102$ & $2 \mathrm{~d}-1 \mathrm{i}$ & $1 \mathrm{~d}-1 \mathrm{i}$ & $28 \mathrm{~d}-22 \mathrm{i}$ & $15 d-9 i$ & $1 \mathrm{i}$ & & $2 d$ & $6 \mathrm{~d}-10 \mathrm{i}$ & $1 d$ & $2 \mathrm{~d}-1 \mathrm{i}$ \\
\hline 6- / 2 & & & & & $2 d$ & & & & & \\
\hline tot./144 & $2 \mathrm{~d}-1 \mathrm{i}$ & $1 d-1 i$ & $33 \mathrm{~d}-28 \mathrm{i}$ & $19 d-16 i$ & $2 \mathrm{~d}-2 \mathrm{i}$ & 1d & $5 d-1 i$ & $11 d-15 i$ & $2 \mathrm{~d}-1 \mathrm{i}$ & $2 \mathrm{~d}-1 \mathrm{i}$ \\
\hline vol.m³ & 29.4 & 16.5 & 10.5 & 3.6 & 0.032 & 0.041 & 0.11 & 61.18 & 37.03 & \\
\hline
\end{tabular}

Tabla 7. Número de valvas de almendra de mar derechas e izquierdas conservadas en los yacimientos romanos de la costa onubense Cerro del Trigo -Almonte- y El Eucaliptal -Punta Umbría- en función de las clases de tamaño expresado por la longitud de la concha en $\mathrm{cm}$

\begin{tabular}{ccccc}
\hline$L M c m$ & $\begin{array}{l}n^{\circ} \text { valvas } d+i \\
C D T\end{array}$ & $\begin{array}{l}n^{\circ} \text { valvas } d+i \\
E P U\end{array}$ & $\begin{array}{l}\text { \% valvas } \\
\text { CDT }\end{array}$ & $\begin{array}{l}\text { \% valvas } \\
\text { EPU }\end{array}$ \\
\hline $0-2$ & 7 & 0 & 4.86 & 0 \\
\hline $2-4$ & 33 & 12 & 22.92 & 15.19 \\
\hline $4-6$ & 102 & 56 & 70.83 & 70.89 \\
\hline $6-$ & 2 & 11 & 1.39 & 13.92 \\
\hline & 144 & 79 & & \\
\hline
\end{tabular}

Tabla 8. Número de valvas de almendras de mar en los cortes realizados en el yacimiento romano de El Eucaliptal en Punta Umbría -costa de Huelva- distribuidas en distintas clases de tamaño expresado por la longitud en $\mathrm{cm}$ de dichas valvas. Se añade el volumen como indicador de las dimensiones del contenedor y de su relación con el contenido

\begin{tabular}{|c|c|c|c|c|c|c|}
\hline $\mathrm{LM} \mathrm{cm} / \mathrm{N}$ & C-E4 & C-E5 & C-G4 & C-I1 & $\mathrm{C}-\mathrm{K} 6$ & TOTAL \\
\hline $0-2 / 0$ & & & & & & 0 \\
\hline $2-4 / 12$ & & $2 d$ & $4 d-4 i$ & & $2 d$ & $8 d-4 i$ \\
\hline 4-6 / 56 & & $2 d$ & $18 d-21 i$ & $1 d$ & $9 d-5 i$ & $30 d-26$ \\
\hline 6- /11 & $1 d$ & $5 d$ & $3 d$ & & $1 d$ & $11 d$ \\
\hline Total / 79 & $1 d$ & $9 d$ & $25 \mathrm{~d} / 25 \mathrm{i}$ & $1 d$ & $12 \mathrm{~d} / 5 \mathrm{i}$ & $49 \mathrm{~d} / 30$ \\
\hline vol. $\mathrm{m}^{3}$ & 28.8 & 8.75 & 8.4 & 3.84 & 72 & \\
\hline
\end{tabular}

Las almendras de mar componen, como ya hemos mencionado, el $75 \%$ de las valvas y conchas halladas en el Cerro del Trigo, siendo posible la medición de la longitud -LM- y la altura -HM- en 144 de ellas y hallando que existen diferencias significativas entre los tamaños de las valvas de un mismo lado distribuidas en desigual número entre las distintas clases de tamaño-tabla 5-.

Analizada la descripción estadística del tamaño de esas valvas en dos dimensiones, altura y longitud de la concha, hemos observado que las medias son similares entre las dos dimensiones y que este tamaño está definido por estas dos ecuaciones que expresan la relación entre la altura $-\mathrm{HM}$ - y la longitud -LM-de las valvas de cada lado, izquierdas -i-y derechas $-\mathrm{d}-$ :

Log HMi $=-0.1532+1.0409$ Log LMi $p=0, r^{2}=97.52 \%, c c=0.987, g \mid=66, S E=0.0464$

Log HMd $=-0.1932+1.0477$ Log LMd $p=0, r^{2}=95.46 \%, c c=0.977, g \mid=76, S E=0.065$

Así que tenemos una asociación de valvas casi igualmente representadas por ambos lados del animal, puesto que de las 144 hay 66 valvas derechas y 78 izquierdas -Tabla 6-, de crecimiento y tamaño muy similares, como mostramos en las ecuaciones anteriores y en la tabla de estadística descriptiva -fig. 9, 10, II y 12-. Esta última característica, el tamaño de las valvas, presenta la particularidad de que el mayor porcentaje de conchas se concentra en la clase de edad adulta del animal entre los 4 y los $6 \mathrm{~cm}$ de longitud, siendo esta última medida el tamaño medio óptimo en la actualidad -tabla 7-. No sólo contamos con estos datos, sino que disponemos de los de El Eucaliptal para comparar - tablas 5 y 8 - y el resultado es que en ambos yacimientos la distribución del tamaño es similar, el mayor porcentaje de valvas se encuentra en la clase de 4 a $6 \mathrm{~cm}$ de longitud, con algo más del 70\% -fig. 12-. Lo que también observamos en la tabla 7 es que hay un mayor porcentaje de almendras con un tamaño superior en El Eucaliptal, si sumamos las clases de tamaño donde se recogen los mayores porcentajes tenemos que el $98.6 \%$ de las valvas derechas e izquierdas recogidas en este segundo sitio tienen un tamaño igual o inferior a $6 \mathrm{~cm}$ de longitud; mientras que en el yacimiento de Punta Umbría aún recogemos casi un $14 \%$ de las valvas con tamaños superiores a los $6 \mathrm{~cm}$ de longitud. Esta diferencia podría tener interpretaciones climatológicas, antrópicas o simplemente no ser significativa, pero la tendremos en cuenta en el estudio que realicemos en los actuales concheros de ambos emplazamientos.

\section{DESPUÉS DE LA BASURA}

Comentan los autores del estudio arqueológico de El Cerro del Trigo (Campos et all., 2001) que las estructuras que sirvieron para casas y fábricas fueron 
abandonadas a medida que la línea de costa retrocedía, con el fin de instalar la población lo más cercana a la fuente de recursos de la población. Este avance implicaba el abandono de las primeras instalaciones, pero en realidad pensamos que, si hubo un aumento de la población, más que un abandono debería existir una sustitución de las funciones del lugar. Por el contrario, una constante población o un decrecimiento de la misma sí que llevaría a un desplazamiento de la misma con el consiguiente abandono de los primeros lugares.

El menor uso de estos terrenos o su total abandono conllevaría una nueva visión del sitio. Allí donde los muros van conteniendo materia orgánica procedente del medio natural, también irían a parar los desechos de la población, tratando los restos de casas como contenedores de basura. Esta capa orgánica va creando nuevos estratos que consolidan el terreno dando lugar a un sustrato más fijo que el de las arenas de las dunas móviles, sobre el que se instaló la población.

Dicho sustrato tiene suficiente potencia para sostener zonas de huertas, hecho que no se ha mencionado, y que quizás el análisis polínico podría confirmar; pero sí fue utilizado este sitio como necrópolis, buscando, probablemente, la perdurabilidad de la que no goza los niveles de arena. Esta sucesión de estratos que disponen al medio para nuevas funciones es un hecho que hemos observado en la ciudad de Sevilla (Bernáldez y Bernáldez, en prensa), en ella observamos cómo las coronas periféricas del casco antiguo amurallado va evolucionando desde zonas de muladares hasta huertas y necrópolis de grupos minoritarios de la población para, finalmente, el espacio ser absorbido por la ciudad, en el caso de crecimiento demográfico.

La materia orgánica provoca la consolidación del medio y debió ser más eficaz enterrar sobre un sustrato fijo que en las arenas. Durante el estudio de formación de depósitos de huesos en la reserva, se observó que en la zona de las dunas había muerta una vaca, en uno de los controles realizados a los pocos meses había desaparecido bajo la arena, pero un año después volvimos a ver el cadáver sobre la duna y casi desenterrado. Es decir, las primeras tumbas de este asentamiento debieron excavarse en el nivel arenoso, experimentando, posiblemente, esta dinámica de continuos enterramientos y desenterramientos que desorientarían la excavación de las siguientes tumbas, a menos que tuviesen alguna señalización de cada una de ellas. Las estructuras abandonadas y la posterior formación de vertederos solucionarían esta inestabilidad del terreno preparándolo para su función como necrópolis y es probable que esto fuese así previsto cuando en los vertederos de este estudio se han encontrado varias tumbas excavadas en los últimos tiempos de este asentamiento, cuando el medio era firme.

Así que no parece algo azaroso la asociación vertederos-necrópolis en estos lugares de estratigrafía tan inestable. Vivir sobre arenas, verter basura sobre rui-
Fig. 10. Clases de tamaño de las valvas de la especie Glycimeris glycimeris. Cerro de Trigo en Doñana. Hay una selección de las almendras de mar de mayor talla podría tener como origen la recolección o la erosión del mar

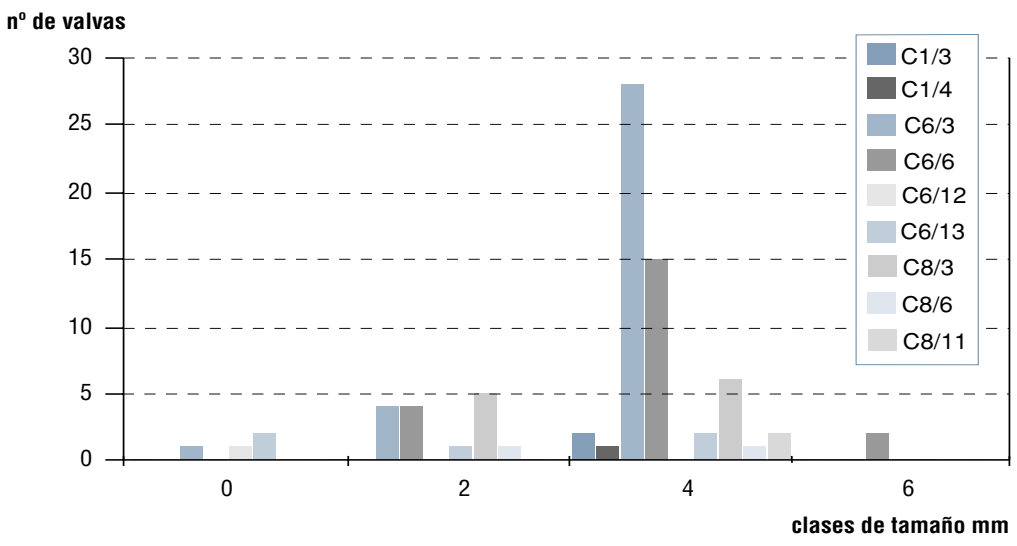

Fig. 11. Clases de tamaño de las valvas de la especie Glycimeris glycimeris. Cerro de Trigo en Doñana. La mayor parte de las valvas de almendras de mar están en las clases de mayor tamaño

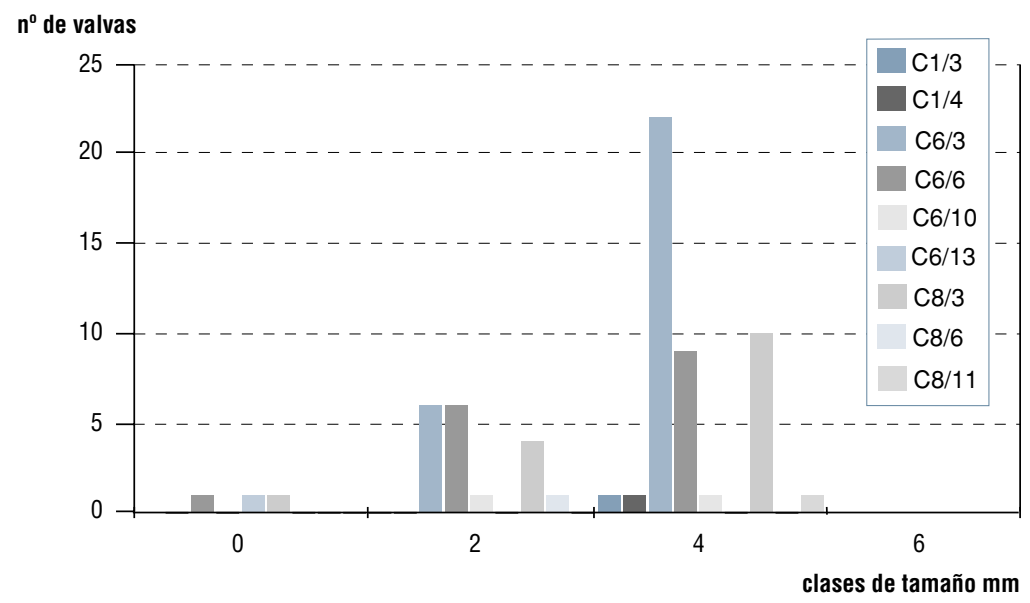

Fig. 12. Tamaño de las Valvas derechas Glycimeris glycimeris. Cerro del Trigo en Almonte y en Punta Umbría. Estudio comparativo de las asociaciones de almendras halladas en los yacimientos romanos de El Eucaliptal en Punta Umbría y del Cerro del Trigo en Ayamonte

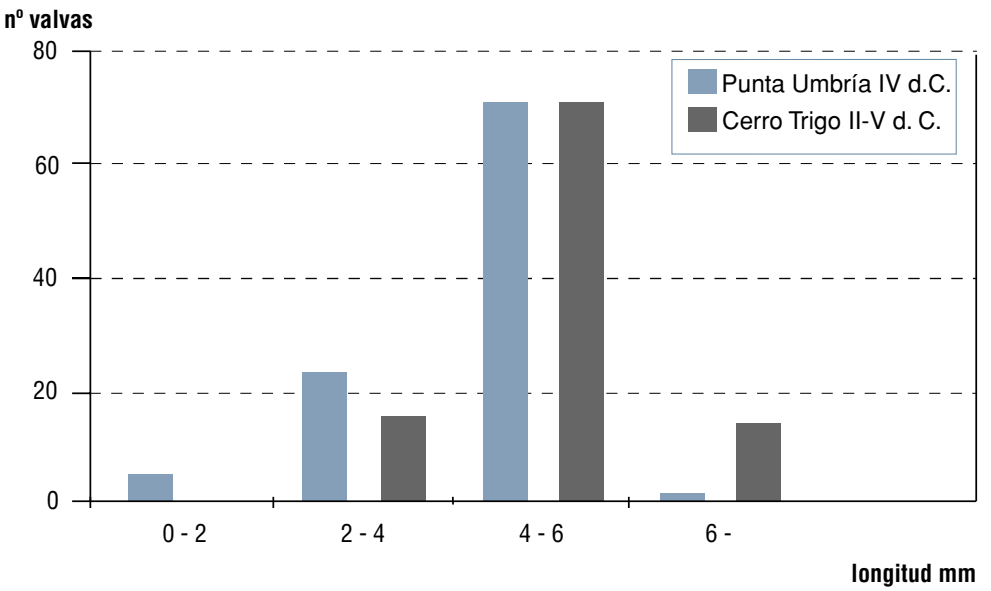

nas y enterrar nuestros muertos sobre la basura transformada en suelo fue un buen mecanismo de reciclaje del espacio de estos antiguos pobladores de El Cerro del Trigo. 
Esta excavación fue realizada por el equipo del Dr. Campos del Área de Arqueología de la Universidad de Huelva. A todos ellos gracias por utilizar unas ciencias, la Paleobiología y la Tafonomía, que han demostrado y deben seguir demostrando que son necesarias para entender nuestro pasado y proyectar desde ahora nuestro futuro.

\section{Referencias bibliográficas}

Bauchot y Pras, 1987. Guía de los peces de mar de España y Europa. Ed. Omega. Barcelona. 43I pp.

Behrensmeyer, A.K. y D.E.D. Boaz, 1980. The recent bones of Amboseli Park, Kenya, in relation to East African Paleoecology. En: Fossils in the Making. Eds. A.K. Behrensmeyer y A.P. Hills. University Chicaco Press.

Bernáldez, E. 1996a. Biestratinomía de los macromamíferos de Doñana. Inferencias ecológicas en los yacimientos arqueológicos del SO de Andalucía. Tesis Doctoral. Universidad de Sevilla.

Bernáldez, E. 1996b. Estudio paleobiológico y tafonómico del yacimiento arqueológico de El Eucaliptal. Informe entregado al Dr. I.M. Campos Carrasco.

Bernáldez, E. 2002a. Bioestratinomy of terrestrial macromammals in Doñana National Park (Spain). En: Current Topics on Tahonomy and Fossilization. Ed. Ayuntamiento y Universidad de Valencia: 315-324.
Bernáldez, E. 2002b. Archaeological garbage dumping sites: a new taphonomic approach. En: Current Topics on Taphonomy and Fossilization. Ed. Ayuntamiento y Universidad de Valencia: 457-470.

Bernáldez, E. y M. Bernáldez (en prensa). Historias orgánicas en la basura del vertedero islámico del Hospital de las Cinco Llagas en Sevilla. Capítulo III. Ed. Parlamento de la Junta de Andalucía.

Campos, J.M.; J.A. Pérez y N. de la O Vidal. 1999. Las cetariae del litoral onubense en época romana. Universidad de Huelva. $222 \mathrm{pp}$.

Campos, J.M., A. Gómez, N. de la O Vidal y J.A. Pérez. 200I. Intervención arqueológica en la factoría romana de El Cerro de Trigo (Doñana, Almonte, Huelva). Memoria de Investigación. Vol. I. Universidad de Huelva. 